\title{
FROM CRISIS TO CONTROL - ALL ABOUT COMMUNICATION?
}

\author{
Åsa Wallström, Lulea University of Technology, Sweden \\ Anne Engström, Lulea University of Technology, Sweden \\ Maria Ek Styvén, Lulea University of Technology, Sweden \\ Esmail Salehi-Sangari, Royal Institute of Technology, Sweden
}

\section{INTRODUCTION}

The supply of drinking water is a crucial and vulnerable element of the Swedish infrastructure. In the past few years it has suffered several crises due to contamination and waterborne diseases. Therefore, management of water crisis has become a highly topical issue for the country's municipalities, particularly after two recent outbreaks of cryptosporidium. This protozoan parasite is often spread through contaminated water and causes a parasitic disease that affects the intestines and typically causes an acute short-term infection. The largest known outbreak of cryptosporidium in drinking water occurred in 1993 in Milwaukee, US, where more than 400000 people were infected. In Sweden, two large outbreaks have occurred during the past few years. The drinking water in Östersund, a mid-sized city with around 59000 inhabitants, was infected with cryptosporidium in November 2010. The number of people infected reached approximately 27 000, and the outbreak lasted for 12 weeks. Just a few months afterwards, Skellefteå, with 71000 inhabitants, had a similar experience. At least 20000 people were infected in an outbreak lasting 20 weeks. This type of crisis affects many people for a long time, and effective communication, therefore, is essential to limit the impact of the crisis.

Previous research has acknowledged the important role communication and public relations play in effective crisis management (e.g., Windsor, 1990; Barton, 1993; Rice, 1990; Rowan, 1991; Williams \& Treadway, 1992; Coombs \& Holladay, 2008; Reynolds, 2006; Tirkkonen \& Luoma-aho, 2011). However, available literature on crisis communication focuses mostly on the private sector, while very little attention is given to crisis communication in the public sector (Horsley \& Barker, 2002). In a crisis situation, municipalities must communicate with employees, citizens and the surrounding community, which can be complex and challenging. Few municipalities have sufficient resources to employ full-time public relations staff to prepare and implement crisis communication plans (Horsley \& Barker, 2002). Several actors become involved when a crisis occurs and many different channels of communication need to be coordinated. Moreover, citizens today play an active role in the dissemination of information, particularly through social media. Thus, during a crisis, municipalities face challenges of coordinating and controlling both internal and external information through many different channels simultaneously, often with limited resources and with a need to reach out to all citizens.

During a crisis the amount of information that needs to be communicated increases. At the same time, the number of channels used is decreasing due to time and resource limitations. Thus, relevant information runs the risk of being delayed or, at worst, does not even reach the intended audience (Hale, Dulek, \& Hale, 2005). Today's technologies provide opportunities to ease these difficulties by making it possible to reach many people quickly and simultaneously through several channels. Recent research has shown that people increasingly view the Internet as the most reliable source of news, especially for timely communication (Liu, Austin, \& Jin, 2011). For example, social media can be used to develop real-time communication with people to build trust and motivate action in crisis situations. Today, the use of social networks and blogs has increased tremendously, and during crises people spend even more time online to search for and share information. People’s changing patterns of behavior imply changes in how organizations effectively reach out to them during a crisis (Liu, Austin, \& Jin, 2011). Even though previous research has shown the benefits of including social media in crisis communication, few organizations have incorporated social media into their strategic communication (Liu, Austin, \& Jin, 2011). Further research should therefore investigate the use and combination of different media to be used in crisis communication, and examine the effectiveness of different channels (Schultz, Utz, \& Göritz, 2011). By understanding the needs, behaviors, and attitudes of various groups of people, municipalities can increase the effectiveness of their internal and external crisis communication. The aim of this study, therefore, is to investigate and compare citizens' and employees' experiences of crisis communication during the outbreak of cryptosporidium in the drinking water of two Swedish cities, Östersund and Skellefteå.

\section{METHODOLOGY}

This study used a combination of qualitative and quantitative methods. Data was collected in several steps to investigate both employees' and citizens' experiences of crisis communication. Firstly, two focus groups were established, with the expert group in a municipality encompassing 14 employees responsible for managing crises and crisis communication. Secondly, six focus groups comprising employees from both cities, were set up. 40 employees from 29 to 65 years of age took part. Thirdly, five 
focus groups were established with citizens from respective cities. In total, 24 citizens aged 18-73 participated in the focus groups. Finally, a postal survey was sent to $1600(800+800)$ randomly sampled citizens between 20-74 years in both cities. 22 envelopes were returned unopened due to wrong address and 66 citizens were withdrawn from the sample since they did not reside in the municipality at the time of the crisis; thus reducing the sample to 1512. In total, 663 completed questionnaires were returned, representing an effective response rate of 44 percent. The survey comprised questions relating to the following topics: sources of information, secondary crisis communication, information quality, communication with the municipality, trust in government, positive meaning, innovativeness, Internet and cellphone behavior, and demographics.

\section{RESULTS AND DISCUSSION}

Results from the focus groups with the experts show that both municipalities acted rapidly and decided to release a "VMA" (important notice to the public) as soon as they suspected a problem with the drinking water. The crisis management team that was formed in each municipality at the outbreak of the crisis included only the core people directly involved in the actual crisis. In fact, the actual composition of the crisis management team turned out to be different from the team that was supposed to be appointed according to the previously established crisis management plan. Communication was perceived as the most important action in taking control of the crisis. Having designated spokespersons throughout the crisis and a clear strategy for public communication were perceived as key factors for managing the crisis. The aim was to take control of the public media through well-planned and continuous press conferences and press releases. In addition to these, the municipality website was perceived to be the most important channel of communication. A critical success factor was to provide open, uniform, and continuous information throughout the crisis, both to media and the public. However, crisis management teams in both cities felt they did not have enough resources or supporting methods to reach out efficiently with internal communication during the crisis.

Results from the focus groups with employees from the two municipalities show that they received the initial information about the water crisis through the "VMA," local newspapers, and friends, and not through internal communication. Employees found the information on the municipality's webpage valuable; however, most of the information was collected through local media and word of mouth. The need for information varied substantially among different groups of employees, depending on their work tasks and what group of citizens they met at work. Results from these focus groups also show that both municipalities lack effective methods to distribute internal information throughout the organization.

Citizens received the initial information regarding the water crisis through the "VMA," local newspapers, and friends. The need for information changed during different phases of the crisis. At the outbreak, citizens needed practical information and facts. During the crisis, citizens wanted to be informed about progress, the source of contamination, and the predicted duration of the crisis. The main information need towards the end of the crisis encompassed assurances that the water was safe to drink, information about the source of contamination, and how the municipality planned to act in order to prevent future water crises. In addition, citizens who had been infected by the parasite experienced a lack of information regarding health-care recommendations. Most citizens perceived the continuous information, available on the municipalities' homepages, as up to date and valuable. However, some citizens, mostly in one of the cities, still suspected that the municipality initially had withheld information, which delayed the first warning messages, and many rumors occurred.

Results from the survey directed at the citizens support the focus groups' findings. Only a few of the citizens (16 percent) perceived a lack of information during the crisis. Information was generally disseminated by talking to friends and colleagues. Only 19 percent of the citizens spread information through social media. Not more than 5 percent of the respondents contacted the municipality during the crisis. However, out of those, the majority (73 percent) had been infected with the parasite or had family members who had been infected. Results show that most citizens trust their municipality and for most citizens (75 percent) their trust has not been affected by the water crisis. However, trust is somewhat lower among citizens who were infected. More than two-thirds of the citizens were willing to register their e-mail addresses and cellphone numbers to receive rapid information from the municipality if a similar crisis occurs in the future. At the same time, 25 percent were unwilling to do so.

\section{CONCLUSION AND IMPLICATIONS FOR THEORY AND PRACTICE}

This study investigated and compared employees' and citizens' experiences of crisis communication during the outbreak of cryptosporidium in the drinking water of two Swedish cities. Many similarities with respect to crisis communication can be found across the two cities. One main difference between the two municipalities was the attention from local and national news. This might be explained by the order of the outbreaks, with the first one receiving much more national coverage. In addition, during this outbreak the World Cup biathlon was taking place in Östersund, which attracted a lot of national and international 
media representatives. Overall, citizens' perceived need for information differed. In one city, citizens were looking for information to establish the source of contamination. This was not an issue in the other city; the focus, instead, was to get information on progress regarding problem solving. A difference could also be found with respect to the citizens' suspicion toward the openness of information from municipalities.

To increase effectiveness in internal crisis communication, municipalities need to develop methods that are easy to use so relevant information can be sent to different groups of employees immediately when a crisis occurs. To succeed with external crisis communication municipalities need to assure transparency with respect to information, take control over media and the flow of information, establish a well-defined crisis communication team and appoint official spokespersons, and produce uniform and continuous information throughout the crisis. In summary, the results of this study show that the water crisis was, to a large extent, a communication crisis. Therefore, the way to take control of the crisis is to control communication.

\section{REFERENCES}

Barton, L. (1993). Crisis in organizations: Managing and communicating in the heat of chaos. Cincinnati, OH: South-Western Publishing Company.

Coombs, W. T., \& Holladay, S. J. (2008). Comparing apology to equivalent crisis response strategies: Clarifying apology's role and value in crisis communication. Public Relations Review, 34(3), 252-257.

Hale, J. E., Dulek, R. E., \& Hale, D. P. (2005). Crisis Response Communication Challenges Building Theory From Qualitative Data. Journal of Business Communication, 42(2), 112-134.

Horsley, J. S., \& Barker, R. T. (2002). Toward a Synthesis Model for Crisis Communication in the Public Sector An Initial Investigation. Journal of Business and Technical Communication, 16(4), 406-440.

Liu, B. F., Austin, L., \& Jin, Y. (2011). How publics respond to crisis communication strategies: The interplay of information form and source. Public Relations Review, 37(4), 345-353.

Rice, R. E. (1990). From adversity to diversity: applications of communication technology to crisis management. Advances in telecommunications management, 3(91-112).

Rowan, K. E. (1991). Goals, obstacles, and strategies in risk communication: A problem-solving approach to improving communication about risks. Journal of Applied Communication Research, 19(4), 300-329.

Schultz, F., Utz, S., \& Göritz, A. (2011). Is the medium the message? Perceptions of and reactions to crisis communication via twitter, blogs and traditional media. Public Relations Review, 37(1), 20-27.

Tirkkonen, P., \& Luoma-aho, V. (2011). Online authority communication during an epidemic: A Finnish example. Public Relations Review, 37(2), 172-174.

Williams, D. E., \& Treadaway, G. (1992). Exxon and the Valdez accident: A failure in crisis communication. Communication Studies, 43(1), 56-64.

Winsor, D. A. (1990). The construction of knowledge in organizations: Asking the right questions about the Challenger. Journal of Business and Technical Communication, 4(2), 7-20. 